\title{
Liver and Plasma Levels of Descarboxyprothrombin (PIVKA II) in Vitamin K Deficiency in Rats
}

\author{
Toshio HARAUCHI, Kyoji TAKANO, Minoru MATSUURA \\ and Toshio YOSHIZAKI \\ Kanzakigawa Laboratory. Shionogi Research Laboratories, Shionogi \& Co., Ltd., \\ Futaba-cho, Toyonaka, Osaka 561, Japan \\ Accepted December 23, 1985
}

\begin{abstract}
Descarboxyprothrombin (PIVKA II) is a precursor of prothrombin without biological activity, and it increases with vitamin $K$ deficiency. We studied the time course changes in liver and plasma levels of PIVKA II during the progress of vitamin $K$ deficiency in rats. Good correlation was observed between liver PIVKA $\|$ and plasma PIVKA $\|$ and between liver or plasma PIVKA II and plasma prothrombin in experiments in which rats were fed a vitamin K-deficient diet. Feeding of a vitamin K-deficient diet or fasting caused marked increases in liver and plasma PIVKA $\mid \mathrm{I}$ in male rats and a weaker response in female rats. Warfarin, a vitamin $\mathrm{K}$ antagonist, caused an abrupt increase in liver PIVKA II, but the increase in plasma PIVKA II was delayed about $3 \mathrm{hr}$. Plasma prothrombin decreased from about 30 min later. Factor VII decreased similarly to prothrombin, and changes in the prothrombin time and activated partial thromboplastin time were slower than the changes in these substances. Sex differences were not seen in these warfarin actions. These observations indicate that liver and plasma PIVKA II are sensitive markers of vitamin K deficiency in rats, and assay of PIVKA $\|$ can be useful for analyzing the action mechanism of drugs which influence blood coagulation.
\end{abstract}

Vitamin $K$ is required in higher animals to regulate the synthesis of prothrombin and three other plasma-clotting factors, VII, IX and $X$. These clotting factors are synthesized from biologically inactive precursor proteins (PIVKA: protein induced by vitamin $K$ absence or antagonists) by $r$-glutamylcarboxylase in liver microsomes (1). As these reactions show no progress in the absence of vitamin $K$ or upon treatment with vitamin $K$ antagonists, an increase in PIVKA reflects the liver state of this vitamin. The precursor protein of prothrombin, descarboxyprothrombin (PIVKA II), is easily excreted into the plasma in humans (2) and cattle (3), but is difficult to excrete in rats $(4,5)$. Recently, certain cephalosporin antibiotics have been reported to cause vitamin K-responsive hypothrombinemia in some patients (6-9). We studied the assay method of PIVKA II in the liver and plasma and studied the relationships between liver and plasma PIVKA II in rats fed a vitamin K-deficient diet or administered warfarin, a vitamin $\mathrm{K}$ antagonist. Prothrombin concentration, factor VII, prothrombin time (PT) and activated partial thromboplastin time (APTT) were determined in some experiments.

\section{Materials and Methods}

Hypothrombinemia was induced in 7- to 8-week-old Sprague-Dawley rats by feeding them a vitamin K-deficient diet (TEKLAD) or by i.p. injection of warfarin. Rats were kept in cages with wire netting on the bottom to prevent coprophagy.

Venous blood was collected from the postcava in a $10 \%$ volume of $3.8 \%$ sodium citrate under Somnopentyl anesthesia (0.5 $\mathrm{ml} / \mathrm{kg}$, i.p.: pentobarbital $\mathrm{Na}, 32.4 \mathrm{mg} / \mathrm{kg}$ ). The blood specimens were centrifuged at $3.000 \times \mathrm{g}$ at $4^{\circ} \mathrm{C}$ for $15 \mathrm{~min}$, and plasma samples were drawn and stored at $-20^{\circ} \mathrm{C}$ until assay. Liver specimens were removed 
and stored at $-70^{\circ} \mathrm{C}$.

One gram of liver tissue was homogenized with a teflon-glass homogenizer in $3 \mathrm{ml}$ of $0.25 \mathrm{M}$ sucrose-0.05 M Tris buffer, $\mathrm{pH} 7.4$. The homogenate was centrifuged at $10,000 \times \mathrm{g}$ for $10 \mathrm{~min}$, and the supernatant was transferred to another tube, diluted with $5 \mathrm{ml}$ of the buffer solution and centrifuged at $105,000 \times \mathrm{g}$ for $60 \mathrm{~min}$. The obtained microsomal fraction was suspended in $1 \mathrm{ml}$ of buffer solution containing 1 part of $3.8 \%$ sodium citrate and 9 parts of $0.15 \mathrm{M} \mathrm{KCl}$ $0.05 \mathrm{M}$ Tris buffer, pH 7.4.

Plasma PIVKA $\|$ and prothrombin were assayed by the method of Suttie et al. (private communication) with a slight modification. As PIVKA II, unlike prothrombin, is not absorbed by insoluble barium salts, the two compounds can be separated. In this method, soluble $\mathrm{BaCl}_{2}$ is used to remove prothrombin instead of insoluble barium salts. In the assay, $25 \mu \mathrm{l}$ of $25 \%$ sodium citrate is added to $1 \mathrm{ml}$ of the plasma with mixing; then $25 \mu l$ of the plasma is transferred to another tube to assay the total amount of prothrombin and PIVKA 11 . Next, $50 \mu \mathrm{l}$ of $1.5 \mathrm{M} \mathrm{BaCl}_{2}$ is added to the remaining plasma with mixing by a vortex for $2 \mathrm{~min}$; then the mixture is centrifuged at about $3,000 \times \mathrm{g}$ for $10 \mathrm{~min}$. The supernatant is transferred to another tube. This procedure is performed twice to ensure removal of prothrombin. The treated plasma contains PIVKA II.

Both treated and untreated plasma were diluted 40- and 400-fold in 0.1 M Tris buffer. $\mathrm{pH}$ 8.3, containing $0.2 \%$ BSA (Buffer $\mathrm{A}$ ), respectively. To $100 / \mu l$ of the diluted plasma was added $0.8 \mathrm{ml}$ of Buffer A containing $10 \mu \mathrm{g}$ of echis carinatus venom and 100 units of Trasylol, and the mixture was preincubated at $37^{\circ} \mathrm{C}$ for $20 \mathrm{~min}$ to convert prothrombin and PIVKA $\|$ to a thrombin-like substance. Next, $100 \mu$ of $1 \mathrm{mM} \mathrm{S-2238,} \mathrm{a}$ chromogenic substrate, was added, and the mixture was incubated at $37^{\circ} \mathrm{C}$ for $10 \mathrm{~min}$. The reaction was stopped by addition of $100 \mu l$ of $20 \%$ sodium dodecyl sulfate, and the amount of $p$-nitroaniline generated from the substrate was measured spectrophotometrically at $405 \mathrm{~nm}$ against a water blank.

Liver PIVKA II was assayed by solubilizing PIVKA II. First, $100 \mu \mathrm{l}$ of $20 \%$ Triton X-100 was added to $1 \mathrm{ml}$ of microsomal suspension, and this mixture was left standing for about $10 \mathrm{~min}$. Next, $100 \mu \mathrm{l}$ of the suspension was transferred for protein determination, and the subsequent procedure was the same as that used for the plasma.

The standard curve was prepared with diluted thrombin to $1.0,0.5,0.25$ and 0.1 unit/ml in Buffer $A$ on log-log paper. The concentrations of prothrombin and PIVKA II were calculated from the standard curve and given as thrombin units per $\mathrm{ml}$ or $\mathrm{mg}$ liver microsomal protein. Protein was determined by the method of Lowry et al. (10).

PT, APTT and factor VII were assayed with COAG-A-MATE-X2 (Warner Lambert), a photo-optical clot detection system based on a one-stage method, using fresh plasma.

Thrombin (Sigma, T-7513), S 2238 (Kabi Diagnostics), echis carinatus venom (Sigma), Trasylol (Bayer) and BSA (Nakarai, fraction v) were used.

\section{Results}

1. Studies on the assay method for PIVKA II: Figure 1 shows a standard curve of thrombin as a straight line from 0.1 to 1.0 unit/ml.

Figure 2 shows the effect of $\mathrm{BaCl}_{2}$ treatment on removal of plasma and liver prothrombin. Although one treatment of plasma and liver samples with $\mathrm{BaCl}_{2}$ did not sufficiently remove prothrombin at any concentration of $\mathrm{BaCl}_{2}$ tested, two treatments

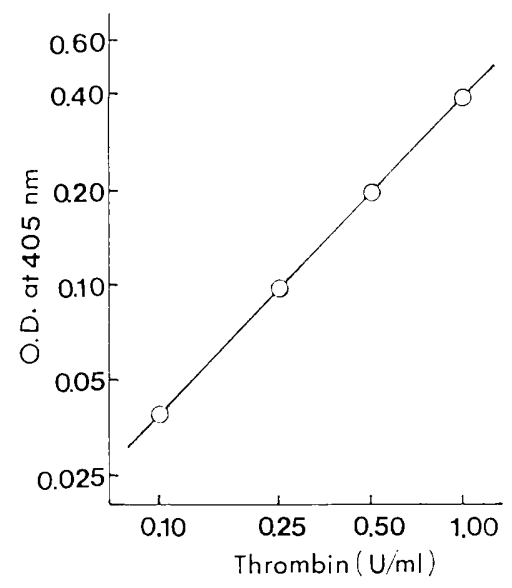

Fig. 1. Standard curve of thrombin. 

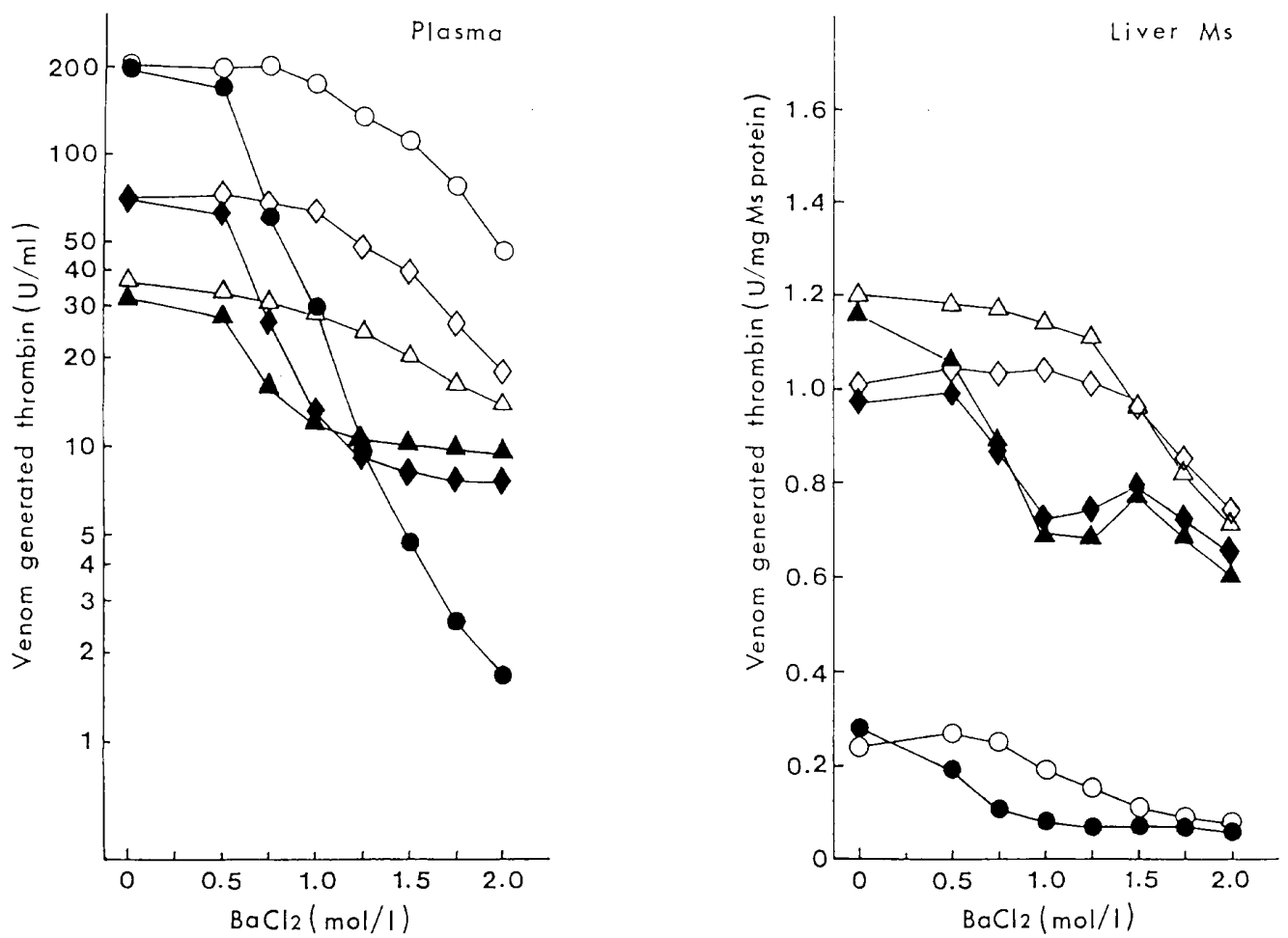

Fig. 2. Effect of $\mathrm{BaCl}_{2}$ concentration on removal of plasma and liver microsomal prothrombin. - $\mathrm{O}$ normal rats, treated once with $\mathrm{BaCl}_{2} ;-\mathbf{O}-$ : normal rats, treated twice with $\mathrm{BaCl}_{2} ;-\triangle-$ : rats fed vitamin $\mathrm{K}$-deficient diet, treated once with $\mathrm{BaCl}_{2} ;-\mathbf{\Delta}-$ : rats fed vitamin $\mathrm{K}$-deficient diet, treated twice with $\mathrm{BaCl}_{2} ;-\diamond-$ : rats administered warfarin, treated once with $\mathrm{BaCl}_{2} ;->$ : rats administered warfarin, treated twice with $\mathrm{BaCl}_{2}$.

with more than $1.5 \mathrm{M}$ of $\mathrm{BaCl}_{2}$ could remove almost all the prothrombin from normal rat plasma and liver. With such $\mathrm{BaCl}_{2}$ treatments, some thrombin activity was detected in the liver and plasma of rats fed a vitamin Kdeficient diet or administered warfarin. These results indicate that there is a small amount of PIVKA II in normal rat liver and plasma and that the increase of PIVKA II is caused in the liver and plasma by vitamin K deficiency.

Table 1 shows the results of solubilization of PIVKA II from liver microsomes by Triton $X-100$ treatment. The amount of PIVKA II in the microsomal extract increased gradually, but the amount per mg protein decreased with an increase in the detergent concentration from 0.25 to $2.00 \%$. This shows that the solubilization ratio of PIVKA II to the other proteins becomes smaller with an increase in the detergent concentration. We tried to measure PIVKA II in the suspension containing the detergent to determine if the extraction was adequate. More PIVKA II was found in the microsomal suspension than in the microsomal extract at all detergent concentrations used, and the amount per mg protein almost reached a plateau level at $1.5 \%$. We decided to use the microsomal suspension to which one-tenth the volume of $20 \%$ Triton $X-100$ was added instead of the microsomal extract.

2. Effect of feeding a vitamin K-deficient diet on PIVKA II: Figure 3 shows the time course changes in liver PIVKA II, PT and APTT in rats fed a vitamin $\mathrm{K}$-deficient diet for 2 to 10 days. In male rats, marked elevation of liver PIVKA II was observed after 2 days of feeding: then a gradual elevation followed until 4 days, when the level reached a plateau. Prolongation of PT was, however, slight at 2 
Table 1. Solubilization of PIVKA II from liver microsomes of rats administered warfarin by treatment of the microsomal fraction with Triton X-100

\begin{tabular}{|c|c|c|c|c|}
\hline \multirow{3}{*}{$\begin{array}{c}\text { Conc. of } \\
\text { Triton } X-100 \\
(\%)\end{array}$} & \multicolumn{4}{|c|}{ Microsomal PIVKA II } \\
\hline & \multicolumn{2}{|c|}{ Extract of Ms fraction ${ }^{2}$} & \multicolumn{2}{|c|}{ Suspension of Ms fraction ${ }^{1}$} \\
\hline & $(\mathrm{U} / \mathrm{ml})$ & $(\mathrm{U} / \mathrm{mg}$ protein) & $(\mathrm{U} / \mathrm{ml})$ & (U/mg protein) \\
\hline 0.25 & 19.8 & 2.10 & 23.7 & 1.34 \\
\hline 0.50 & 20.6 & 2.00 & 23.5 & 1.32 \\
\hline 1.00 & 20.4 & 1.68 & 25.2 & 1.43 \\
\hline 1.50 & 20.8 & 1.63 & 24.8 & 1.52 \\
\hline 2.00 & 21.0 & 1.60 & 25.3 & 1.52 \\
\hline
\end{tabular}

Ms: Microsomes. 'The microsomal fraction was suspended in buffer solution containing 1 part of $3.8 \%$ sodium citrate and 9 parts of $0.15 \mathrm{M} \mathrm{KCl}-0.05 \mathrm{M}$ Tris buffer, $\mathrm{pH} 7.4$, using a Teflon-glass Potter type homogenizer; and PIVKA II was solubilized by addition of 0.1 vol. of various concentrations of Triton $X$ 100 solutions to $0.9 \mathrm{vol}$. of the suspension in order to gain the mentioned final concentration of the detergent. ${ }^{2}$ The supernatant of the above-described microsomal suspension containing Triton $\mathrm{X}-100$ obtained by centrifugation at $105,000 \times \mathrm{g}$ for $60 \mathrm{~min}$.
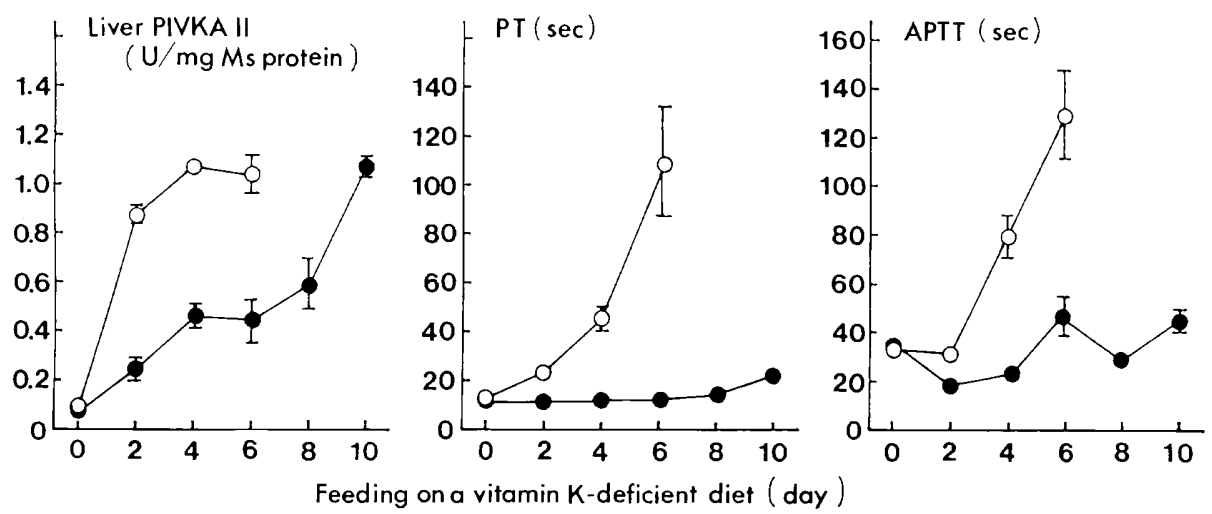

Fig. 3. Changes in liver PIVKA II, prothrombin time (PT) and activated partial thromboplastin time (APTT) in rats fed a vitamin K-deficient diet. Each point represents the mean \pm S.E.M. of 9 rats. Most of the male rats in the groups of 8 and 10 days could not tolerate the test periods and the data are excluded from this figure. $-\mathrm{O}-$ : males, $-\mathbf{O}-$ : females.

days of feeding, gradual until 4 days, and then marked. On the other hand, in female rats, the increase in liver PIVKA II was gradual and prolongation of PT and APTT was slight in 10 days of feeding.

Figure 4 shows the correlation between liver PIVKA II and plasma PIVKA II or prothrombin in rats fed a normal diet and those fed a vitamin $\mathrm{K}$-deficient diet. The correlation coefficients between liver and plasma PIVKA II, liver PIVKA II and plasma prothrombin, and plasma PIVKA II and prothrombin indicated good reciprocity, with the reciprocity being best between liver PIVKA II and plasma prothrombin.
3. Effect of fasting on PIVKA II levels: Table 2 shows the effect of fasting on plasma and liver PIVKA II, plasma prothrombin and PT. Fasting for only a day caused an increase in plasma and liver PIVKA II and a decrease in prothrombin and prolongation of PT in male rats, and there were slight changes in female rats with 2 days of fasting.

4. Effect of warfarin administration on PIVKA II levels: Figure 5 shows the changes in liver and plasma PIVKA II, plasma prothrombin and PT after administration of warfarin. Female rats showed similar changes to male rats, with liver PIVKA $\|$ rapidly increasing within 3 to $6 \mathrm{hr}$ at which time the 

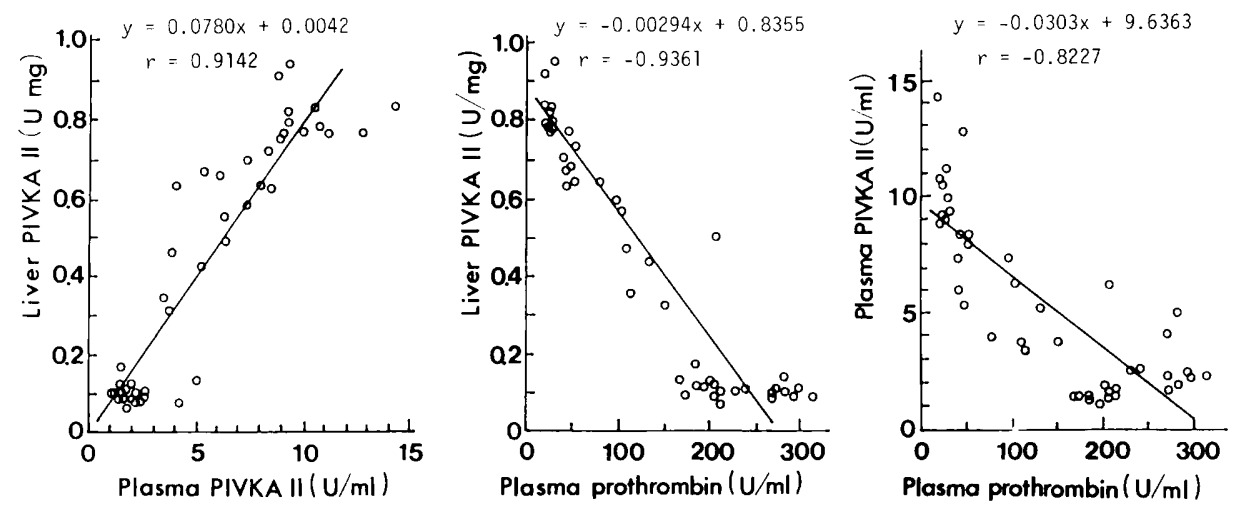

Fig. 4. Correlation between liver PIVKA II and plasma PIVKA II, liver PIVKA II and plasma prothrombin. and plasma PIVKA II and prothrombin. Rats were fed a vitamin K-deficient and normal diet.

Table 2. Effects of fasting on the levels of prothrombin. PIVKA II and prothrombin time in rats

\begin{tabular}{|c|c|c|c|c|c|c|}
\hline \multirow[b]{2}{*}{ Sex } & \multirow[b]{2}{*}{$\begin{array}{l}\text { Fasting } \\
(\mathrm{hr})\end{array}$} & \multirow[b]{2}{*}{$\begin{array}{l}\text { No. of } \\
\text { rats }\end{array}$} & \multirow{2}{*}{$\begin{array}{l}\text { Prothrombin } \\
\text { plasma } \\
(\mathrm{U} / \mathrm{ml})\end{array}$} & \multicolumn{2}{|c|}{ PIVKA II } & \multirow{2}{*}{$\begin{array}{c}\text { Prothrombin } \\
\text { time } \\
(\mathrm{sec})\end{array}$} \\
\hline & & & & $\begin{array}{l}\text { Plasma } \\
(\mathrm{U} / \mathrm{ml})\end{array}$ & $\begin{array}{c}\text { Liver } \\
\text { (U/mg Ms protein) }\end{array}$ & \\
\hline \multirow[t]{3}{*}{ Male } & Control & 5 & $198.6 \pm 6.8$ & $2.3 \pm 0.1$ & $0.08 \pm 0.00$ & $10.0 \pm 0.1$ \\
\hline & 24 & 5 & $125.0 \pm 13.7^{* *}$ & $3.2 \pm 0.2^{* *}$ & $0.46 \pm 0.04^{* *}$ & $11.2 \pm 0.3^{*}$ \\
\hline & 48 & 5 & $64.8 \pm 16.2^{* *}$ & $6.1 \pm 1.1^{*}$ & $0.47 \pm 0.08^{* *}$ & $13.9 \pm 1.1^{*}$ \\
\hline \multirow[t]{3}{*}{ Female } & Control & 5 & $218.9 \pm 8.4$ & $1.3 \pm 0.1$ & $0.08 \pm 0.00$ & $9.9 \pm 0.0$ \\
\hline & 24 & 5 & $189.0 \pm 12.9$ & $1.8 \pm 0.2$ & $0.07 \pm 0.00$ & $9.8 \pm 0.1$ \\
\hline & 48 & 5 & $179.9 \pm 6.3^{*}$ & $1.5 \pm 0.2$ & $0.09 \pm 0.01$ & $10.0 \pm 0.1$ \\
\hline
\end{tabular}

Data represent the mean \pm S.E.M. * Significantly different from the control at $\mathrm{P}<0.05$. ${ }^{*}$ "Significantly different from the control at $\mathrm{P}<0.01$.

level reached a plateau level. The increase in plasma PIVKA $\|$ within $3 \mathrm{hr}$ was slight, and then the level increased until $24 \mathrm{hr}$. The plasma level of prothrombin fell sharply within $6 \mathrm{hr}$ and then gradually until $24 \mathrm{hr}$. Prolongation of PT was slight until $6 \mathrm{hr}$, then gradually increased until $24 \mathrm{hr}$.

Figure 6 shows the results of dose studies on liver PIVKA $\|$, plasma PIVKA $\|$ and plasma prothrombin in male rats. There were slight differences between the doses for the maximal levels of plasma and liver PIVKA II and the minimal level of plasma prothrombin. and for the number of hours required to reach these levels, but the duration of their maximal or minimal levels was longer with higher doses. The changes in PT, APTT and factor VII in these experiments are shown in Fig. 7. The decrease in factor VII was similar to that of prothrombin, but prolongation of PT and APTT was dose-dependent.

\section{Discussion}

Prothrombin content can be determined by a spectrophotometric method $(11,12)$, by coagulation assay (13) in which thrombin is generated by physiological or non-physiological activation, and by immunological assay (14). As PIVKA $\|$ and prothrombin are activated by treatment with echis carinatus venom, PIVKA II can be determined by prothrombin assay methods after separation of prothrombin $(4,5,15,16)$. We employed the method of Suttie et al. (private communication) for plasma PIVKA II. This method is a modification of the spectrophotometric method using a chromogenic substrate (5) and differs in that $\mathrm{BaCl}_{2}$ is used instead of $\mathrm{BaSO}_{4}$ to separate prothrombin. Prothrombin may be absorbed on the insoluble barium citrate formed or it may be precipitated by chelation with barium ion. 

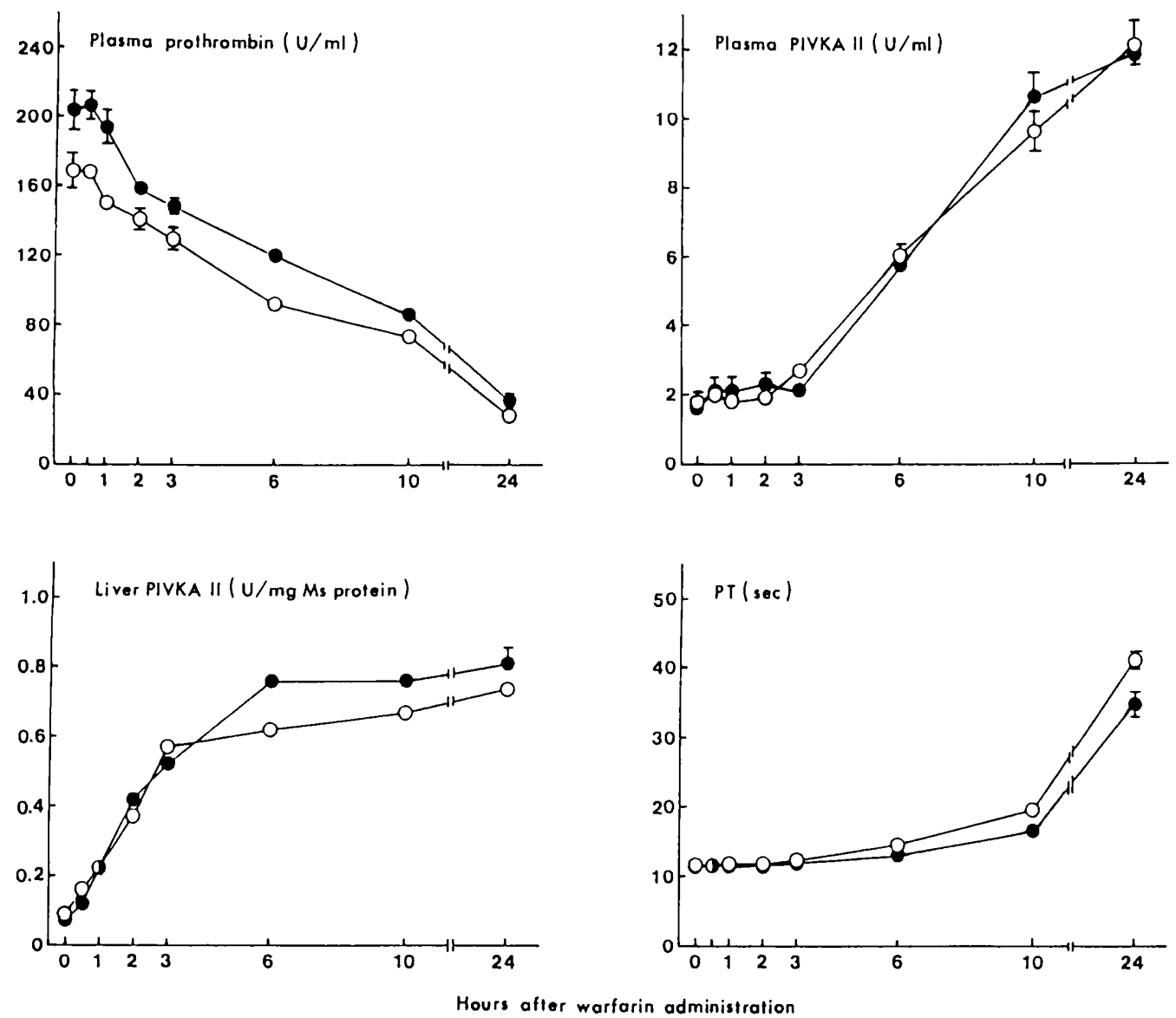

Fig. 5. Changes in liver and plasma PIVKA II, plasma prothrombin and prothrombin time (PT) after i.p. administration of $2.5 \mathrm{mg} / \mathrm{kg}$ of warfarin in rats. Each point represents the mean \pm S.E.M. of 5 rats. - $\bigcirc-$ : males, - - : females.

$\mathrm{BaCl}_{2}$ has been used to remove prothrombin by others (17), but detailed data were not given. Our experiments gave good results for differential estimation of PIVKA II and prothrombin. This method is also convenient for routine assay because $\mathrm{BaCl}_{2}$ dissolves in water. Plasma and liver samples can be stored in a freezer for at least 1 month until assay. To assay liver PIVKA II, a microsomal suspension containing Triton $X 100$ is better than the solubilized extract as assay samples and is also convenient for routine assay.

Good correlation was observed between liver PIVKA II and plasma PIVKA II, liver PIVKA II and plasma prothrombin, and plasma PIVKA $\|$ and prothrombin in the experiments with rats fed a vitamin K- deficient diet. These observations indicate that liver and plasma PIVKA $\|$ are good markers of vitamin $\mathrm{K}$ deficiency in rats.

Vitamin $K$ deficiency produces hypoprothrombinemia, and male rats are more susceptible to vitamin $\mathrm{K}$ deficiency than female rats (18-22). In our experiments, even 2 days feeding of a vitamin K-deficient diet or 1 or 2 days fasting caused a marked increase in liver and plasma PIVKA II as well as a decrease in plasma prothrombin in male rats, suggesting that the pool of vitamin $\mathrm{K}$ is very small in male rats. In female rats, only slight changes in these proteins were observed under the same conditions, indicating that they are more resistant to vitamin $\mathrm{K}$ deficiency.

Vitamin K-dependent carboxylation of 

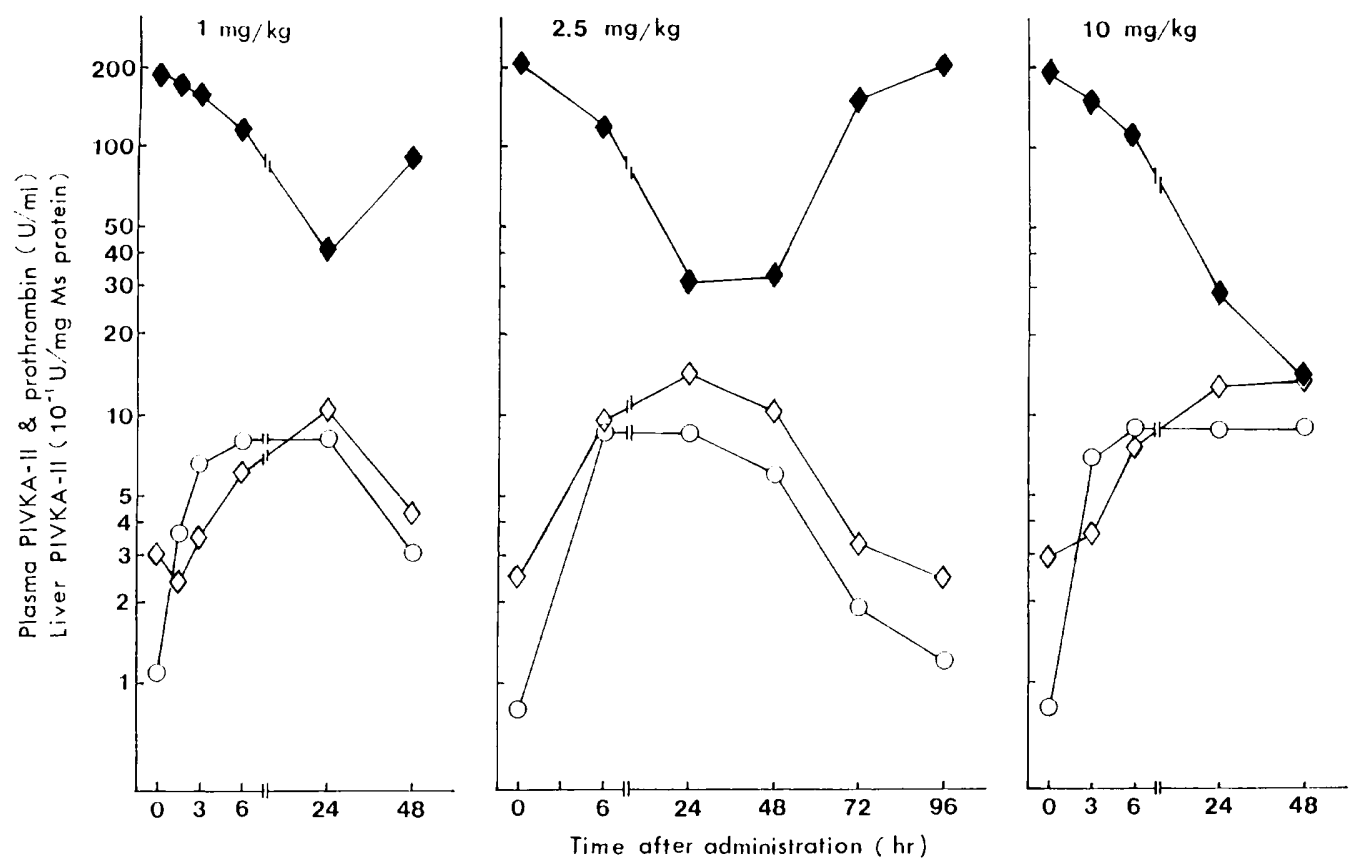

Fig. 6. Dose studies of warfarin on liver PIVKA II, plasma PIVKA II and plasma prothrombin in male rats. Each point represnts the mean \pm S.E.M. of 5 rats. $-\mathrm{O}$-: liver PIVKA II, $-\diamond-$; plasma PIVKA II. $-\longrightarrow$ : plasma prothrombin.

PIVKA II occurs in liver microsomes and requires a hydroquinone form of vitamin $\mathrm{K}$. Liver microsomes have a vitamin $\mathrm{K}$ cycle in which the hydroquinone form can be successively converted into its 2,3-epoxide, the quinone form and the hydroquinone form (1). Warfarin is thought to exhibit its anticoagulant action by inhibiting the process from the 2,3-epoxide to the quinone form and from the quinone to the hydroquinone form. Marked changes in plasma prothrombin and liver PIVKA II occurred even $1.5 \mathrm{hr}$ after administration of $1 \mathrm{mg} / \mathrm{kg}$ of warfarin. There were slight differences between warfarin doses for changes in plasma levels of PIVKA II and prothrombin and liver levels of PIVKA II until a plateau or minimum was reached and their maximal or minimal values attained, but the duration of the maximal or minimal level was dose-dependent. These observations suggest that complete inhibition of hydroquinone synthesis of vitamin $\mathrm{K}$ occurs in a dose range of 1 to $10 \mathrm{mg} / \mathrm{kg}$ and also that the turnover of the vitamin $\mathrm{K}$ cycle is very quick. No difference between male and female rats was observed for changes in prothrombin, PIVKA II and PT after inhibition of the synthetic pathway of the hydroquinone form in a vitamin $\mathrm{K}$ cycle by warfarin administration. This shows that there is no sex difference in hydroquinone consumption and in the responsibility of vitamin K-dependent carboxylation of PIVKA $\|$ to the hydroquinone. Therefore, the sex difference in the resistance to vitamin $\mathrm{K}$ deficiency seems to be due to a difference in the supply of the hydroquinone. A possible cause of the difference may be a sex difference in intestinal absorption of vitamin $K$, which can be inferred from the experimental result that estrogen facilitates intestinal absorption of vitamin $K(21)$ or a sex difference in consumption of the quinone form of vitamin $\mathrm{K}$ through unknown pathways.

In spite of the abrupt increase in liver PIVKA II, the rise in the plasma level was very slight until $3 \mathrm{hr}$ after administration of warfarin. Liver PIVKA 11 reached a plateau level $6 \mathrm{hr}$ later, but $24 \mathrm{hr}$ was needed to reach the plateau level in the plasma. These time 

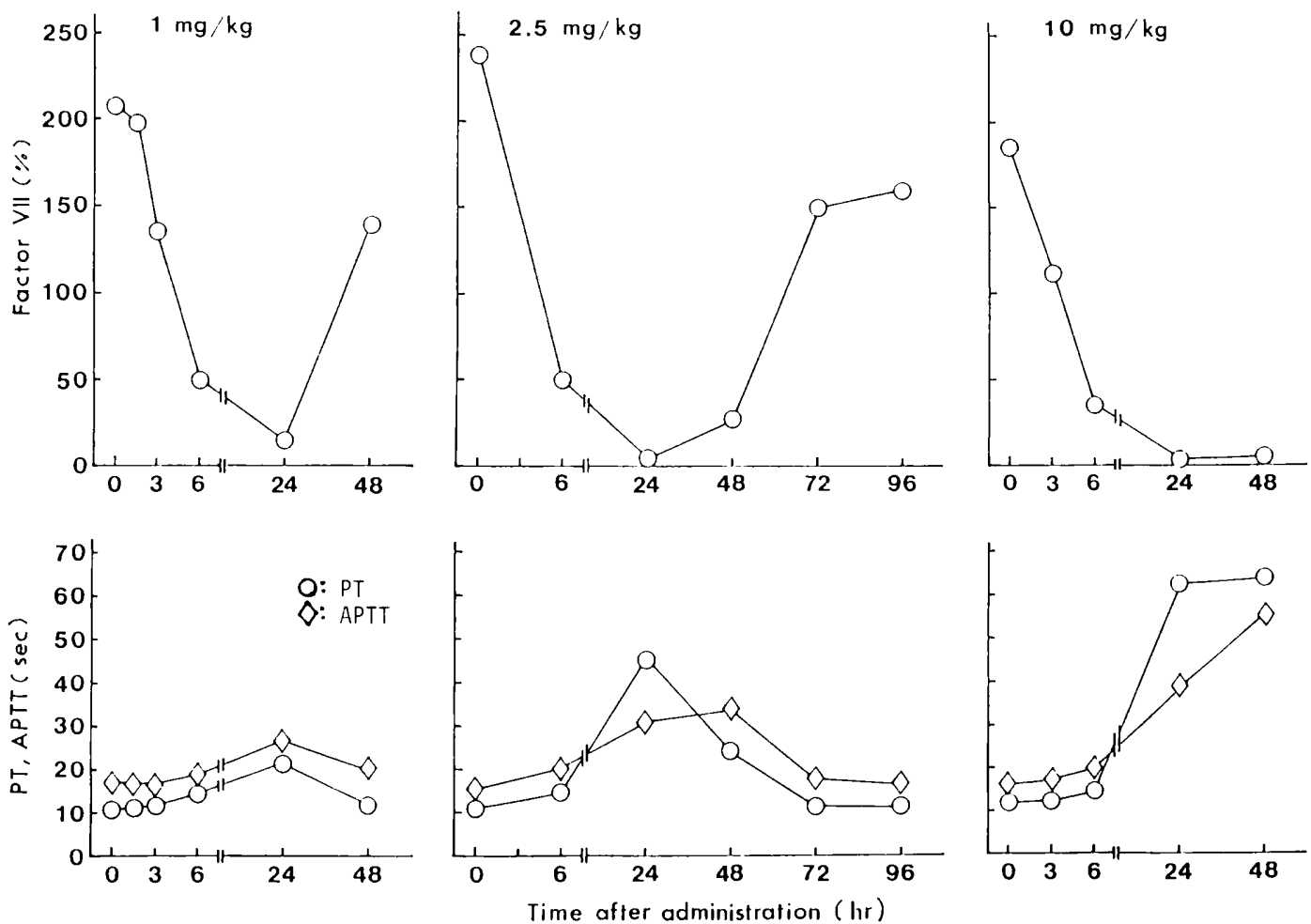

Fig. 7. Dose studies of warfarin on prothrombin time (PT), activated partial thromboplastin time (APTT) and plasma factor VII in male rats. Warfarin was administered i.p. to rats. Each point represents the mean \pm S.E.M. of 5 rats.

lags between liver and plasma PIVKA II suggest that there may be a threshold for release of PIVKA II from the liver to the blood.

In rats fed a vitamin K-deficient diet or administered warfarin, the increase in PT or APTT was slower than the changes in PIVKA II and prothrombin. Increases in PT and APTT were dose-dependent, but slight differences were observed for the increase in PIVKA $\|$ and the decrease in prothrombin among warfarin dosages from 1 to $10 \mathrm{mg} / \mathrm{kg}$. A living body may have clotting factors to spare, or changes of PT or APTT may not coincide with changes in the clotting factors because they reflect the composite result of plural clotting factors.

In conclusion, increases in plasma and liver PIVKA II sharply reflect the vitamin Kdeficient status, and the latter is more sensitive than the former in rats. As PIVKA II has a high specificity for vitamin K deficiency. assay of plasma and liver PIVKA II may be useful for analyzing the action mechanism of drugs which have an influence on blood coagulation.

Acknowledgement: The authors wish to thank Dr. Kiyohisa Uchida for his helpful suggestions. We are also grateful to Prof. J. W. Suttie, Department of Biochemistry, College of Agricultural and Life Sciences, University of Wisconsin-Madison, for kindly giving us the assay manual of plasma PIVKA II.

\section{References}

1 Suttie, J.W.: Mechanism of action of vitamin K: Synthesis of $\gamma$-carboxyglutamic acid. CRC Crit. Rev. Biochem. 8, 191-223 (1980)

2 Ganrot, P.O. and Nilehn, J.E.: Plasma prothrombin during treatment with Dicumarol. II. Demonstration of an abnormal prothrombin fraction. Scand. J. Clin. Lab. Invest. 22, 23-28 (1968)

3 Stenflo, J.: Dicumarol-induced prothrombin in bovine plasma. Acta Chem. Scand. 24, 37623763 (1970) 
4 Carlisle, T.L., Shah, D.V., Schlegel, R. and Suttie, J.W.: Plasma abnormal prothrombin and microsomal prothrombin precursor in various species. Proc. Soc. Exp. Biol. Med. 148, 140144 (1975)

5 Shah, D.V., Swanson, J.C. and Suttie, J.W.: Abnormal prothrombin in the vitamin $\mathrm{K}$ deficient rat. Thromb. Res. 35, 451-458 (1984)

6 Reddy, J. and Baily, R.R.: Vitamin K deficiency developing in patients with renal failure treated with cephalosporin antibiotics. N. Z. Med. J. 672, 378-379 (1980)

7 Hooper, C.A., Haney, B.B. and Stone, H.H.: Gastrointestinal bleeding due to vitamin $K$ deficiency in patients on parenteral cefamandol. Lancet i, 39-40 (1980)

8 Weitekamp, R.M. and Aber, R.C.: Prolonged bleeding times and bleeding diathesis associated with moxalactam administration. JAMA 249, 69-71 (1983)

9 Haubenstock, A., Schmidt, P., Zazgornik, J., Balcke, P. and Kopsa, H.: Hypoprothrombinaemic bleeding associated with ceftriaxone. Lancet i, 1215-1216 (1983)

10 Lowry, O.H., Rosebrough, N.J., Farr, A.L. and Randall, R.J.: Protein measurement with the Folin phenol reagent. J. Biol. Chem. 193, 265275 (1951)

11 Axelsson, G., Korsan-Bengtsen, K. and Waldenstöm, J.: Prothrombin determination by means of a chromogenic peptide substrate. Thromb. Haemost. 36, 517-524 (1976)

12 Bertina, R.M., van der Marel-van Nieuwkoop, W. and Loeliger, E.A.: Spectrophotometric assays of prothrombin in plasma of patients using orat anticoagulants. Thromb. Haemost. 42, 12961305 (1979)

13 Shapiro, S.S. and Waugh, D.F.: The purification of human prothrombin. Thrombos. Diathes.
Haemorrh. 16, 469-490 (1966)

14 Swanson, J.C. and Suttie, J.W.: Vitamin K dependent in vitro production of prothrombin. Biochemistry 21, 6011-6018 (1982)

15 Jesso, F., Lavergne, J.M., Gouault, M., ProvWartele, O. and Soulier, J.P.: Differents états moléculaires du facteur II (prothrombine). Leur étude a l'aide de la staphylocoagulase et d'anticorps anti-fecteur II. Thrombos. Diathes. Haemorrh. 20, 88-98 (1968)

16 Suttie, J.W.: Mechanism of action of vitamin K: demonstration of a liver precursor of prothrombin. Science 179, 192-194 (1973)

17 Bechtold, H., Andrassy, K., Jahnchen, E., Koderisch, J., Koderisch, H., Weilemann, L.S., Sonntag, H.-G. and Ritz, E.: Evidence for impaired hepatic vitamin $K_{1}$ metabolism in patients treated with $\mathrm{N}$-methylthiotetrazole cephalosporins. Thromb. Haemost. 51, 358361 (1984)

18 Metta, V.C. and Johnson, C.: Effect of feeding vitamin K-deficient diets to female rats. J. Nutrition 72, 455-458 (1960)

19 Mellette, S.J.: Interrelationships between vitamin $\mathrm{K}$ and estrogenic hormones. Am. J. Clin. Nutr. 9, 109-116 (1961)

20 Matschiner, J.J. and Bell, R.G.: Effect of sex and sex hormones on plasma prothrombin and vitamin $\mathrm{K}$ deficiency. Proc. Soc. Exp. Biol. Med. 144, 316-320 (1973)

21 Jolly, D.W., Craig, C. and Nelson, T.E., Jr.: Estrogen and prothrombin synthesis: effect of estrogen on absorption of vitamin $K_{1}$. Am. J. Physiol. 232, H12-H17 (1977)

22 Uchida, K., Shike, T., Kakushi, H., Takase, H., Nomura, Y., Harauchi, T. and Yoshizaki, T.: Effect of sex hormones on hypoprothrombinemia induced by $\mathrm{N}$ - methyltetrazolethiol in rats. Thromb. Res. 39, 741-750 (1985) 